\title{
KAJIAN DESA TERTINGGAL MENURUT KEPUTUSAN MENTERI DESA PEMBANGUNAN DAERAH TERTINGGAL NOMOR 3 TAHUN 2016
}

\author{
Pieter Fredison Erasmus Benany ${ }^{1)}$, Anak Agung Sagung Alit Widyastuty ${ }^{2)}$ \\ 1) ${ }^{2}$ Fakultas Teknik Sipil dan Perencanaan, Universitas PGRI Adi Buana Surabaya \\ Email: piterbenany@gmail.com
}

\begin{abstract}
Abstrak
Kecamatan Maurole merupakan salah satu kecamatan yang terletak di bagian utara Kabupaten Ende Provinsi Nusa Tenggara Timur, yang memiliki luas 196,36 km² terdiri dari 13 desa, 120 RT, $51 \mathrm{RW}$ dan 39 Dusun dengan kepadatan penduduk 892,7 orang/km2. Kecamatan Maurole memiliki 4 desa yang dikategorikan sebagai desa tertinggal menurut Peraturan Menteri Pembangunan Daerah Tertinggal Nomor 126 Tahun 2017 tentang Penetapan Desa Prioritas Sasaran Pembangunan Desa, Pembangunan Daerah Tertinggal dan Transmigrasi. Desa-desa tersebut antara lain: Desa Ranokolo, Desa Keliwumbu, Desa Woloau dan Desa Ngalukoja. Tujuan penelitian ini adalah mengidentifikasi kondisi fisik, sosial dan ekonomi di Kecamatan Maurole. Berdasarkan Keputusan Menteri Desa Pembangunan Daerah Tertinggal Nomor 3 Tahun 2016 tentang Petunjuk Teknis Penentuan Indikator Dalam Penetapan Daerah Secara Nasional. Penelitian ini menggunakan metode analisis deskriptif kualitatif dan teknik presentase dengan menggunakan metode pengumpulan data melalui observasi, literasi dan dokumentasi. Hasil analisis menunjukan bahwa, berdasarkan 12 kriteria kondisi fisik penentu desa tertinggal, 4 desa tertinggal di Kecamatan Maurole telah mengalami perkembangan pada tahun 2018 antara lain Desa Ranokolo 83\%, Desa Keliwumbu 83\%, Desa Woloau 58\% dan Desa Ngalukoja 58\%. Berdasarkan 6 kriteria kondisi sosial ekonomi penentu desa tertinggal, 4 desa tertinggal di Kecamatan Maurole masih berkembang sebesar $50 \%$.
\end{abstract}

Kata Kunci: Desa Tertinggal, Keputusan Menteri Desa, Pembangunan Daerah Tertinggal dan Transmigrasi No. 3 Tahun 2016.

\section{Abstract}

Maurole District is one of the districts located in the northern part of Ende Regency, East Nusa Tenggara Province, which has an area of $196.36 \mathrm{~km}^{2}$ consisting of 13 villages, $120 \mathrm{RT}, 51 \mathrm{RW}$ and 39 hamlets with a population density of 892.7 people / km2. Maurole Subdistrict has 4 villages categorized as underdeveloped villages according to Regulation of the Minister of Underdeveloped Regions Number 126 Year 2017 concerning the Determination of Priority Villages for the Target of Village Development, Underdeveloped Regional Development and Transmigration. The villages include: Ranokolo Village, Keliwumbu Village, Woloau Village and Ngalukoja Village. The purpose of this study is to identify the physical, social and economic conditions in the District of Maurole. Based on the Decree of the Village Minister for Disadvantaged Regions Number 3 of 2016 concerning Technical Guidelines for Determination of Indicators in the Determination of Regions Nationally. This research uses descriptive qualitative analysis methods and percentage techniques using data collection methods through observation, literacy and documentation. The analysis showed that, based on 12 criteria for determining the physical condition of underdeveloped villages, 4 underdeveloped villages in Maurole Subdistrict had experienced developments in 2018 including Ranokolo Village 83\%, Keliwumbu Village 83\%, Woloau Village 58\% and Ngalukoja Village 58\%. Based on 6 criteria for determining socioeconomic conditions of underdeveloped villages, 4 underdeveloped villages in Maurole sub-district are still developing by 50\%.

Keywords: Underdeveloped Village, Village Minister Decree, Underdeveloped Regional Development and Transmigration No. 3 of 2016. 


\section{PENDAHULUAN}

Kecamatan Maurole merupakan salah satu kecamatan yang berada di bagian utara Kabupaten Ende Provinsi Nusa Tenggara Timur. Kecamatan Maurole memiliki luas $196,36 \mathrm{~km}^{2}$ terdiri dari 13 desa, $120 \mathrm{RT}, 51$ RW dan 39 Dusun dengan kepadatan penduduk 892,7 orang/km2.

Keputusan Menteri Desa, Pembangunan Daerah Tertinggal dan Transmigrasi Nomor 126 Tahun 2017 tentang Penetapan Desa Prioritas Sasaran Pembangunan Desa, Pembangunan Daerah Tertinggal Dan Transmigrasi, Kecamatan Maurole teridentifikasi memiliki desa-desa yang terkategori sebagai desa tertinggal antara lain : Desa Ranokolo (nilai indeks 49,35), Desa Keliwumbu(nilai indeks 47,28), Desa Ngalukoja (nilai indeks 44,53) dan Desa Woloau (nilai indeks 44,73).

Kondisi sarana dan prasarana desa tertinggal di Kecamatan Maurole masih belum memadai. Jenis permukaan jalan desa $81 \%$ berupa perkerasan tanah, dengan akses menuju ibu kota kecamatan yang terjauh adalah Desa Woloau, dengan jarak $22 \mathrm{~km}$.Ketersediaan sarana kesehatan desa tertinggal masih sangat minim yaitu perdesa hanya terdapat satu fasilitas kesehatan berupa Puskesmas Pembantu (Pustu) dan Pos Pelayanan Keluarga Berencana Kesehatan Terpadu (Posyandu) sedangkan fasilitas kesehatan utama Puskesmas berada di ibu kota kecamatan. Karakteristik daerah desa tertinggal di Kecamatan Maurole termasuk daerah rawan bencana gempa, gelombang pasang, dan banjir karena letak kondisi geografisnya yang berada di dataran rendah pinggiran pantai khususnya Desa Keliwumbu dan Desa Ngalukoja (Kecamatan Maurole Dalam Angka 2018).

Berdasarkan masalah yang telah diangkat,maka tujuan yang akan di capai dalam penelitian yaitu untuk Mengidentifikasi kondisi fisik dan sosial ekonomi desa tertinggal di Kecamatan Maurole dengan ruang lingkup subtansif, 1). Kondisi fisik : rata-rata jarak dari kantor desa ke kantor kabupaten, persentase desa dengan jarak pelayanan kesehatan, rata-rata jarak dari desa ke pusat pelayanan pendidikan dasar, jalan utama desa dengan jenis permukaan jalan utama terluas aspal/beton, di perkeras, tanah dan permukaan jalan utama luas lainnya. rumah tangga pengguna telepon, rumah tangga pengguna listrik, rumah tangga pengguna air bersih, pasar tanpa bangunan permanen/semi permanen, sarana dan prasarana kesehatan per 1000 penduduk, jumalah dokter per 1000 penduduk, jumlah SD, SMP per seribu penduduk dan karakteristik daerah. 2). Kondisi sosial ekonomi : Persentase Penduduk miskin, pengeluaran konsumsi perkapita, angka harapan hidup, rata-rata lama sekolah, angka melek huruf dan keuangan daerah.

Menurut Keputusan Menteri Desa, Pembangunan Daerah Tertinggal Nomor 3 Tahun 2016 tentang Petunjuk Teknis Penentuan Indikator Dalam Penetapan Daerah Tertinggal Secara Nasional. Dalam menetapkan status suatu daerah tertinggal dilihat dari enam kriteria utama dapat dilihat pada Tabel 1.

Tabel 1. Kriteria Penetapan Daerah Tertinggal

\begin{tabular}{cl}
\hline \multicolumn{2}{c}{ Kriteria Penetapan Daerah Tertinggal } \\
\hline \multirow{2}{*}{ Prekonomian masyarakat } & Persentase penduduk miskin \\
& Pengeluaran konsumsi perkapita \\
\hline \multirow{2}{*}{ Sumber daya manusia } & Angka harapan hidup. \\
& Rata-rata lama sekolah \\
& Angka melek huruf \\
\hline
\end{tabular}

Jalan utama desa dengan jenis permukaan jalan utama

Sarana prasarana terluas aspal/beton,

Jalan utama desa dengan jenis permukaan jalan utama desa terluas di perkeras, 
Jalan utama desa dengan jenis permukaan jalan utama desa terluas tanah

Jalan utama desa dengan permukaan jalan utama luas lainnya.

Rumah tangga pengguna telepon

Rumah tangga pengguna listrik.

Rumah tangga pengguna air bersih

Pasar tanpa nanguna permanen/semi permanen.

Sarana dan prasana keehatan per seribu penduduk

Jumlah dokter perseribu penduduk.

Jumlah SD, SMP, per seribu penduduk

Kemampuan keuangan daerah.

Rata-rata jarak dari kantor desa ke kantor kabupaten

$\begin{array}{ll}\text { Aksesbilitas } & \text { Persentase desa dengan jarak pelayanan kesehatan } \geq \\ 5 \mathrm{~km}\end{array}$

Sumber : Keputusan Menteri Desa, Pembangunan Daerah Tertinggal No 3 Tahun 2016

Desa tertinggal adalah desa yang memiliki potensi sumber daya sosial, ekonomi, dan ekologitetapi belum, atau kurang mengelolanya dalam upaya peningkatan kesejahteraan masyarakat desa, kualitas hidup manusia serta mengalami kemiskinan dalam berbagai bentuknya. ( Peraturan Menteri Desa, Pembangunan Daerah Tertinggal dan Transmigrasi Nomor 19 Tahun 2017, tentang Penetapan Prioritas Penggunaan Dana Desa Tahun 2018). 
Berdasarkan pengertian desa tertinggal di atas dapat disimpulkan bahwa desa tertinggal adalah suatu wilayah yang dimana pembangunannya belum optimal baik pembangunan fisik maupun non fisik serta memiliki kendala, dimana di lihat dari sarana prasarana (infrastruktur),keuangan daearah,prekonomian masyarakat, SDM yang masih lemah.

Faktor penyebab daerah tertinggal antara lain: 1). Secara geografis,relatif sulit di jangkau karena letaknya yang jauh di pedalaman, perbukitan/pegunungan, kepulauan, pesisir, dan pulau pulau terpencil atau karena faktor geomorfologis lainnya sehingga sulit di jangkau oleh jaringan baik transportasi maupun media komunikasi. 2). Dari sisi sumber daya alam, tidak memiliki potensi, atau memiliki sumber daya alam besar namun lingkungan sekitarnya merupakan daerah yang di lindungi atau tidak dapat dieksploitasi,dan daerah tertinggal akibat eksploitasi sumber daya alam yang berlebihan. 3). Dari sisi sumber daya manusia, umumnya masyarakat di daerah tertinggal, tingkat pendididkan,pengetahuan dan keterampilannya relatif rendah serta kelembagaan adat yang belum berkembang. 4). Keterbatasan prasarana dan sarana komunikasi tranportasi, air bersih, irigasi, kesehatan pendidikan , dan pelayanan lainnya yang menyebabkan kesulitan untuk melakukan aktifitas ekonomi dan sosial. 5). Seringnya (suatu daerah) mengalami bencana alam dan konflik sosial yang berakibat terganggunya kegiatan pembangunan sosial dan ekonomi. 6). Suatu daerah menjadi tertinggal, disebabkan oleh beberapa kebijakan yang tidak tepat,seperti: kurang memihak pada pembangunan daerah tertinggal,kesalahan pendekatan dan prioritas pembangunan,serta tidak dilibatkanya kelembagaan masyarakat adat dalam perencanaan dan pembangunan. (Bappenas, 2006 dalam Muhtar dkk,2011).

\section{METODE}

Rancangan penelitian yang di gunakan dalam penelitian Kajian daerah Tertinggal di Kecamatan Maurole Kabupaten Ende Berdasarkan Keputusan Menteri Desa, Pembangunan Daerah Tertinggal Nomor 3 Tahun 2016 tentang Petunjuk Teknis Penentuan Indikator Dalam Penetapan Daerah Secara Nasional adalah dengan menggunakan metode deskriptif kualitatif. Menurut Sukmadinanta (2011) dalam Gae (2018), kualitatif di tujukan untuk mendeskripsikan dan menggambarkan fenomena-fenomena yang ada, baik bersifat ilmiah maupun rekayasa, keterkaitan antar kegiatan. Metode Pengumpulan data dalam penelitian ini terdiri dari atas survey primer dan Survey sekunder.

Metode analisis mengidentifikasi kondisi fisik, sosial dan ekonomi desa tertinggal menggunakan analisis deskriptif kualitatifdan teknik presentase yang menjelaskan tentang kondisi eksisting lokasi study desa tertinggal, di peroleh dari hasil survey primer dan sekunder. Data yang di perlukan antara lain, kondisi fisik : 1). rata-rata jarak dari kantor desa ke kantor kabupaten. 2). persentase desa dengan jarak pelayanan kesehatan. 3). rata-rata jarak dari desa ke pusat pelayanan pendidikan dasar. 4). jalan utama desa dengan jenis permukaan jalan utama terluas aspal/beton, di perkeras, tanah dan permukaan jalan utama luas lainnya. 5). rumah tangga pengguna telepon. 6). rumah tangga pengguna listrik. 7). rumah tangga pengguna air bersih. 8). pasar tanpa bangunan permanen/semi permanen. 9). sarana dan prasarana kesehatan per 1000 penduduk. 10). jumlah dokter per 1000 penduduk. 11). jumlah SD, SMP per seribu penduduk. 12). karakteristik daerah. Kondisi sosial ekonomi : 1). persentase Penduduk miskin. 2). pengeluaran konsumsi perkapita. 3). angka harapan hidup. 4). rata-rata lama sekolah. 5) angka melek huruf. 6). keuangan daerah. 


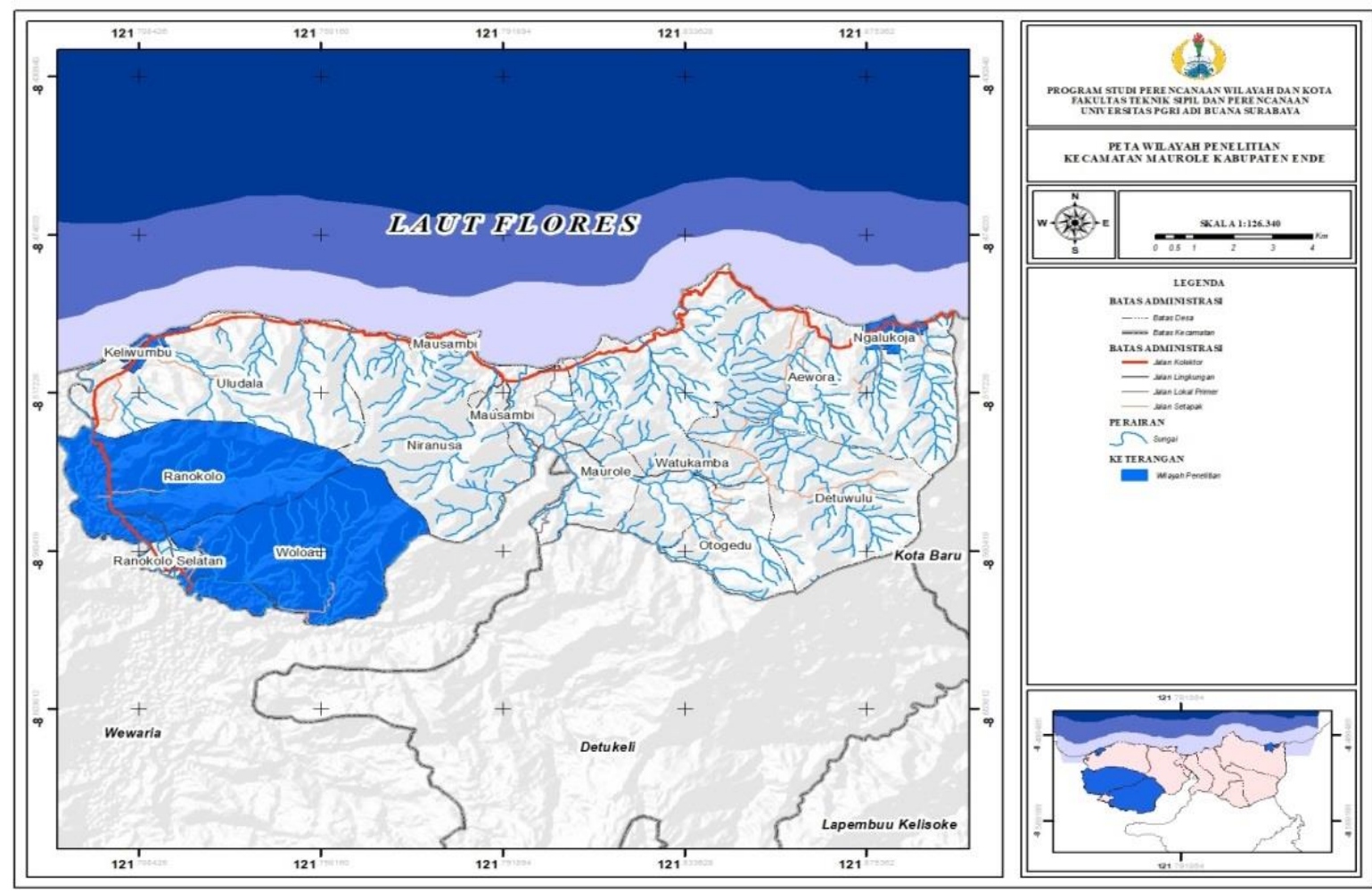

Gambar 1. Peta Wilayah Penelitian Desa Tertinggal Kecamatan Maurole

\section{HASIL DAN PEMBAHASAN}

1) Rata-rata jarak dari kantor desa ke kantor kabupaten.

Secara keseluruhan rata- rata jarak dari kantor desa tertinggal terjauh adalah Desa Ngalukoja yakni $96 \mathrm{Km}$.

2) Persentase desa dengan jarak pelayanan kesehatan $\geq 5 \mathbf{~ k m}$

Ketersediaan pelayanan kesehatan desa tertinggal masih sangat minim, Desa Ranokolo terdapat satu Poskedes yang hanya berjarak 200 meter, dan Desa Keliwumbu juga memiliki satu pustu dengan jarak 100 meter, sedangkan Desa Woloau dan Desa Ngalukoja tidak memiliki fasilitas kesehatan selain Posyandu untuk Bayi dan Balita

3) Rata-rata jarak dari desa ke pusat pelayanan pendidikan dasar.

Berdasarkan data diatas rata-rata jarak pelayanan pendidikan sekolah dasar di desa tertinggal sudah memenuhi syarat desa membangun, karena jaraknya yang relative dekat yaitu 50- 800 meter dengan waktu tempuh \pm 15 menit tentunya mempermudah anak-anak yang mau mempuh sekolah dasar untuk mendapat pelayanan pendidikan.
4) Jalan utama desa dengan jenis permukaan jalan utama terluas

aspal/beton, di perkeras, tanah dan permukaan jalan utama luas lainnya.

Secara keseluruhan jenis permukaan jalan utama desa tertinggal sudah dalam kondisi baik. Jenis permukaan jalan utama Desa Ranokolo terdiri dari aspal seluas 3 meter dengan panjang $4 \mathrm{Km}$ Jenis permukaan jalan utama Desa Keliwumbu terdiri dari aspal seluas 3 meter, yang merupakan jalan kabupaten dan juga jalan penghubung antar desa dengan sepanjang $3 \mathrm{Km}$, jalan tanah 4 $\mathrm{Km}$, jalan berbatu $2 \mathrm{Km}$ dan jalan tanah $1 \mathrm{Km}$. Jenis permukaan jalan utama Desa Woloau terdiri dari semen beton seluas 3 meter dengan panjang jalan $7 \mathrm{Km}$ dan Desa Ngalukoja terdiri dari aspal seluas 3 meter dan panjang jalan 1 $\mathrm{Km}$.

\section{5) Rumah tangga pengguna telepon}

Berdasarkan hasil penelitian pada tahun 2018 ini, rata- rata semua masyarakat desa tertinggal di Kecamatan Maurole telah menggunakan telepon genggam. Berdasarkan jarak dan letak ketinggian wilayah diatas permukaan air laut 100- $500 \mathrm{~m}$, Desa Ngalukoja sulit di jangkau oleh sinyal karena lokasi BTS berada pada Desa mausambi dengan ketinggian terendah $13 \mathrm{~m}$ diatas permukaan air laut. 


\section{6) Rumah tangga pengguna listrik.}

Persentase penggunaan listrik di Desa Ranokolo pengguna listrik sebesar 79,5\% dan non listrik sebesar 20,4\%, Desa Keliwumbu pengguna listrik 99\% dan non listrik 1\% sedangkan Desa Woloau dan Desa Ngalukoja rata-rata telah terlayani $100 \%$. Meningkatnya pelayanan listrik di desa tertinggal pada tahun 2018 ini tentunya berpengaruh pada kegiatan sehari-hari masyarakat desa tertinggal dalam hal menunjang prekonomian, social dan budaya

7) Rumah tangga pengguna air bersih.

Dari data 2018 penggunan air bersih di desa tertinggal rata-rata sudah terlayani. Desa Ranokolo terdapat 205 KK, Desa Keliwumbu 218 KK, Desa Woloau 168 KK dan Desa Ngalukoja 139 KK. Sumber air bersih berasal dri PDAM yang berada pada Desa Watukamba.

\section{8) Pasar tanpa bangunan permanen/semi permanen.}

Berdasarkan data hasil penelitian 2018 rata-rata desa tertinggal di Kecamatan Maurole tidak memiliki pasar, lokasi pasar berada pada desa lainya Desa Ranokolo Selatan, Desa Maurole, Desa Aewora dan Desa Uludala. Berdasarkan kondisi yang ada di lapangan pasar yang memilki bangunan permanen yaitu di Desa Maurole dan Desa Keliwumbu. Untuk itu perlunya penambahan pasar tradisional agar masyarakat desa tertinggal dapat memenuhi kebutuhan pokok sehari hari.

\section{9) Sarana dan prasarana kesehatan per 1000 penduduk.}

Sarana kesehatan di desa tertinggal Desa Ranokolo terdapat 1 Poskesdes/Polindes, Desa Keliwumbu terdapat 1 pustu, sedangkan Desa Woloau dan Desa Ngalukoja tidak memiliki sarana kesehatan terdekat, untuk itu perlu adanya pembangunan sarana kesehatan terdekat desa tertinggal agar masyarakat desa bisa memenuhi pelayanan kesehatan yang dekat dan baik.

\section{0) Jumalah dokter per 1000 penduduk}

Desa tertinggal di Kecamatan Maurole tidak memilki dokter, berdasarkan masalah di perlunya penambahan tenaga medis berupa dokter di tiap desa tertinggal

11) Jumlah SD, SMP per seribu penduduk.

Berdasarkan data 2018 rata-rata desa tertinggal telah memiliki memiliki SD dan SMP berada pada Desa Keliwumbu. Dengan meningkatnya pembangunan pelayanan sekolah dasar dan sekolah menengah pertama di desa tertinggal mempermudah masyarakat untuk mendapat pelayanan pendidikan yang baik.

\section{2) Karakteristik daerah}

Berdasarkan 7 kriteria diatas dan penelitian desa tertinggal di Kecamatan Maurole hanya Desa woloau yang pernah terjadi bencana banjir di tahun 2017 yakni mengakibatkan kondisi jalan rusak sepanjang $9 \mathrm{Km}$ dan \pm 60 rumah terendam banjir. Hal ini menunjukan bahwa desa Woloau rentan terhadap bencana banjir karena letak jalan yang miring dari gunung ke lembah sampai jalan utama desa, dan juga tidak memiliki drinase sama sekali.

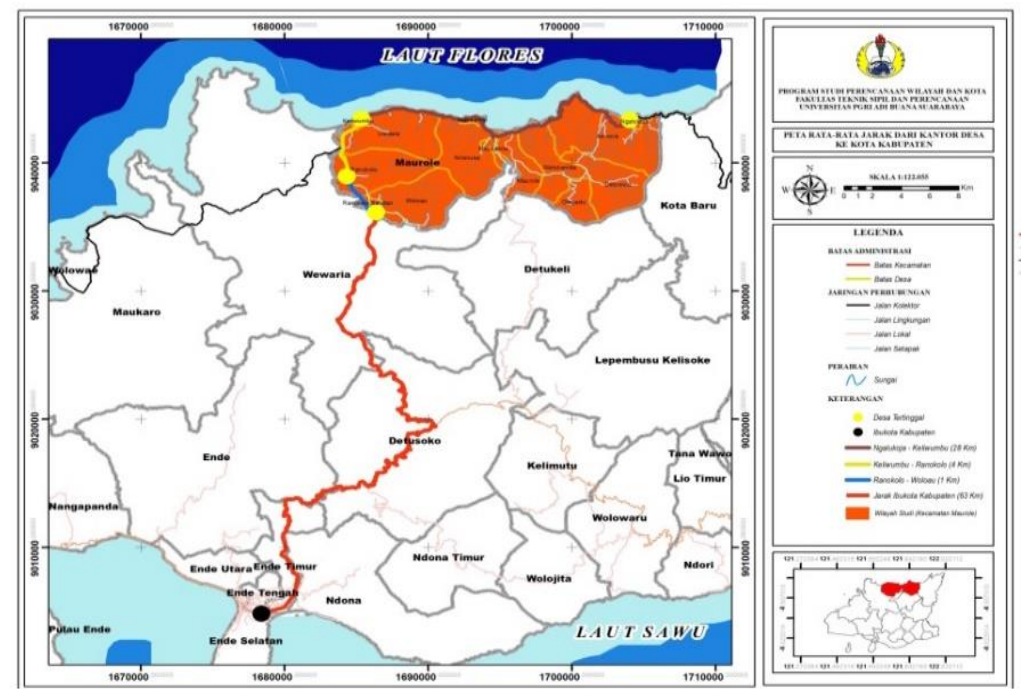

Gambar 2. Peta Rata- rata Jarak Dari Kantor Desa ke Kabupaten 


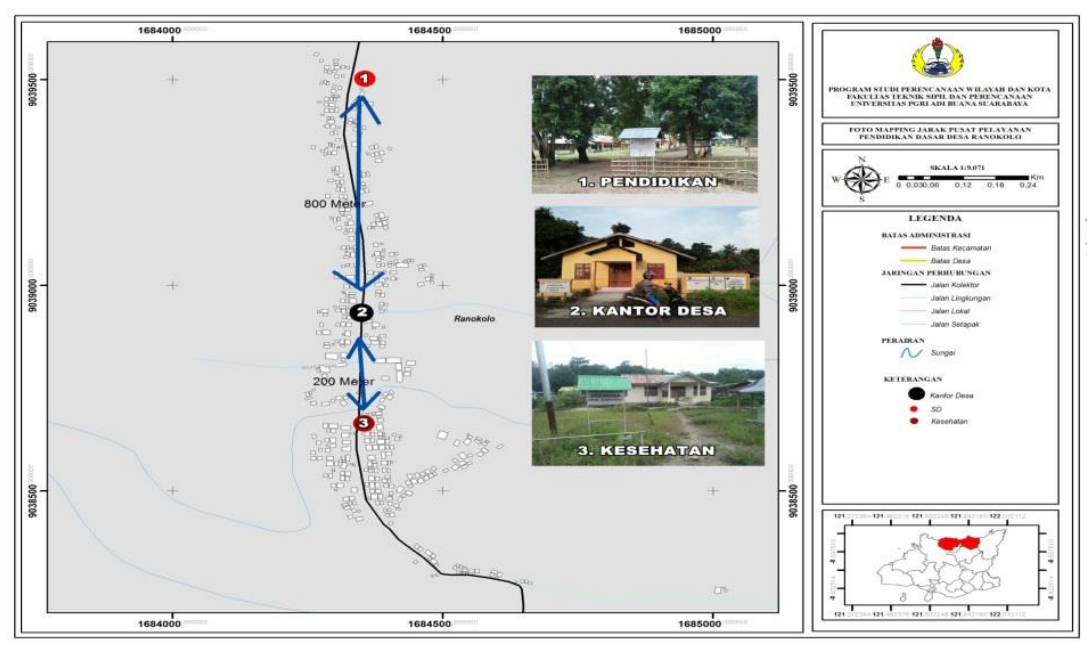

Gambar 3. Foto Mapping Jarak Pelayanan Pendidikan dasar dan Kesehatan Desa Ranokolo

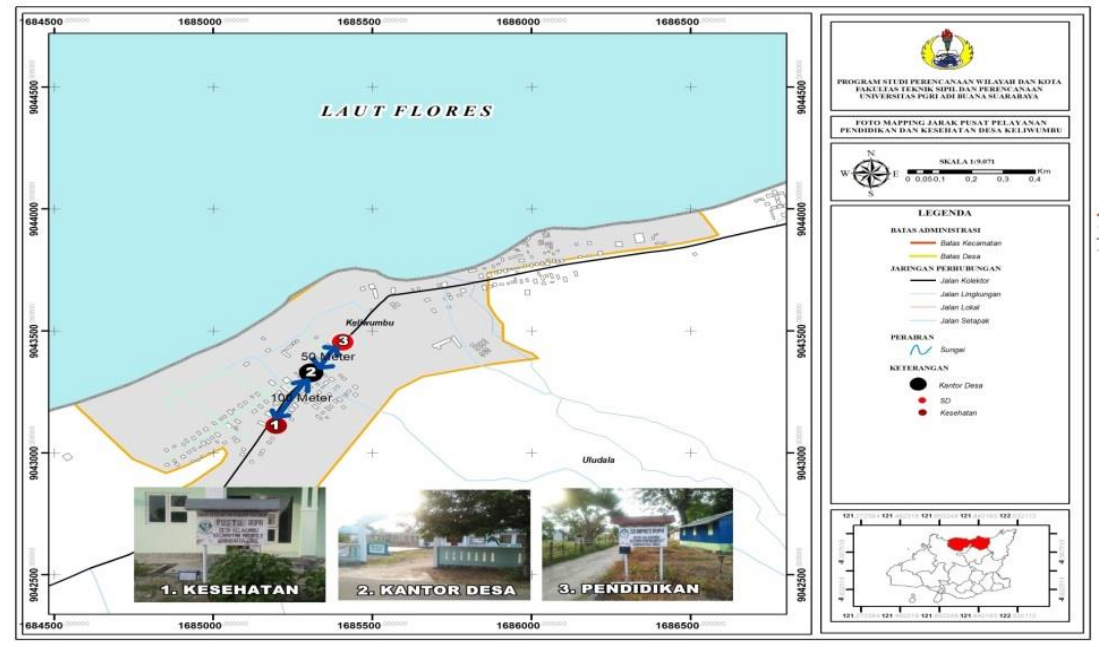

Gambar 4. Peta MappingJarak Pelayanan Pendidikan dasar dan Kesehatan Desa Keliwumbu

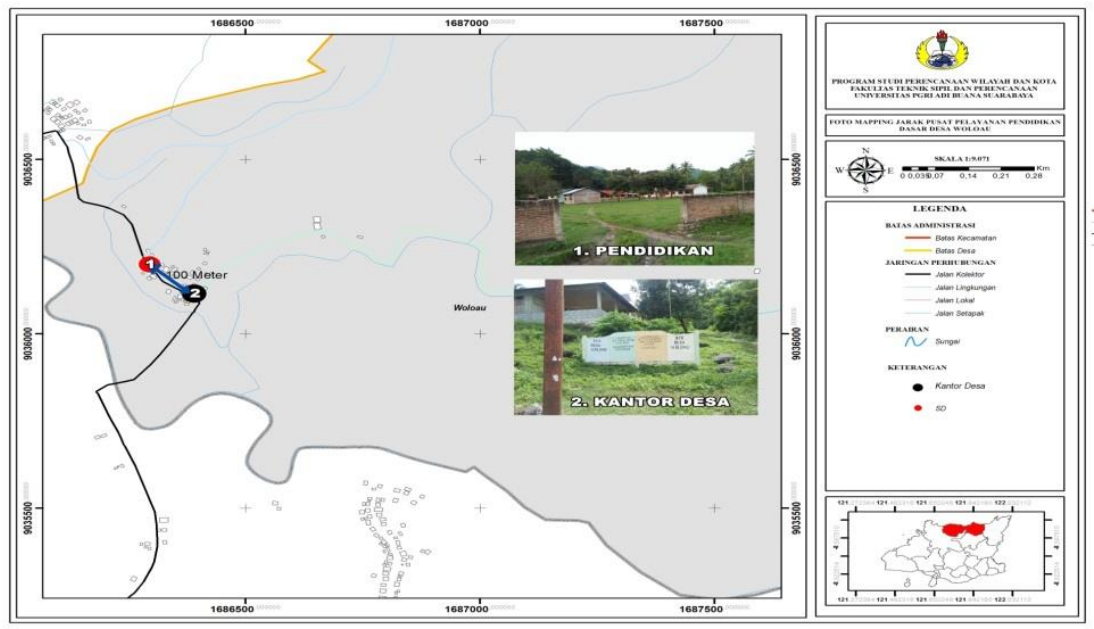

Gambar 5. Peta Mapping Jarak Pelayanan Pendidikan dasar Desa Woloau 


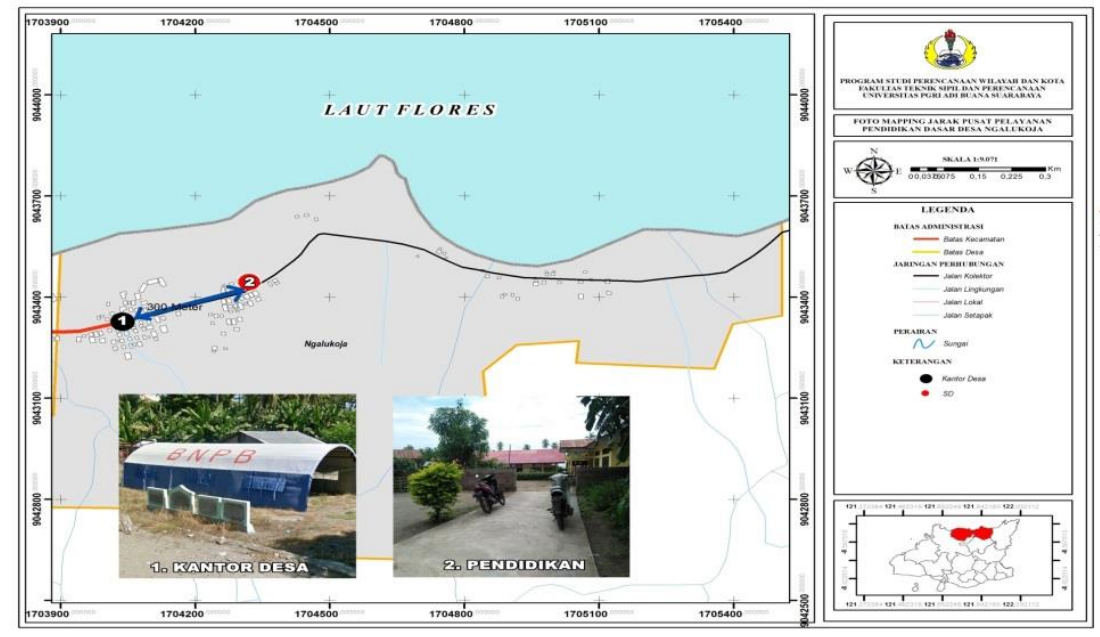

Gambar 6. Peta Mapping Jarak Pelayanan Pendidikan dasar Desa Ngalukoja

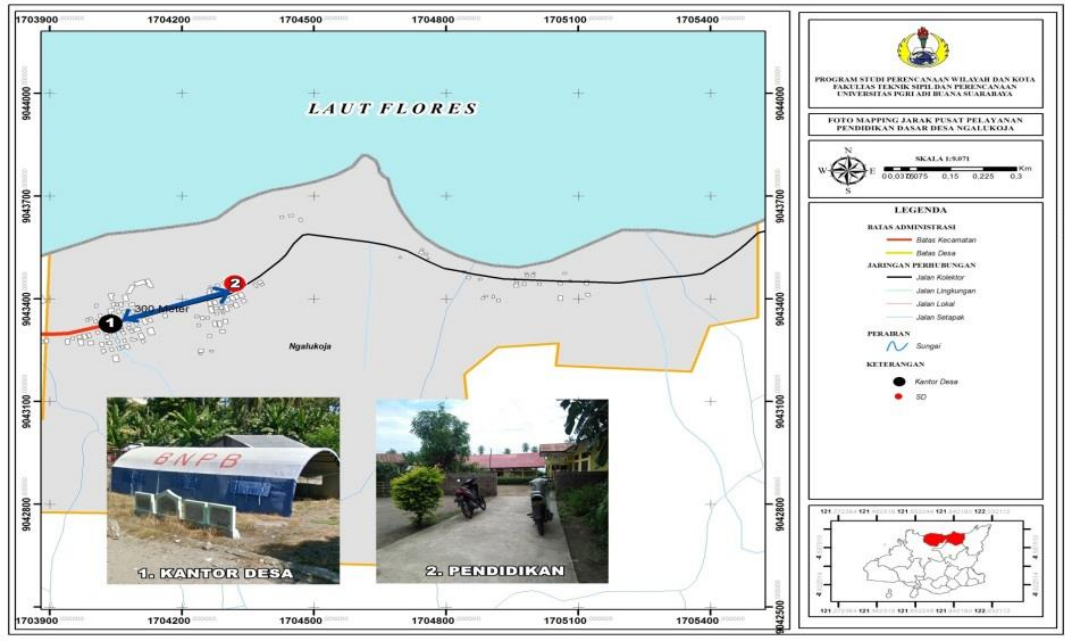

Gambar 7. Peta Mapping Jarak Pelayanan Pendidikan dasar Desa Ngalukoja

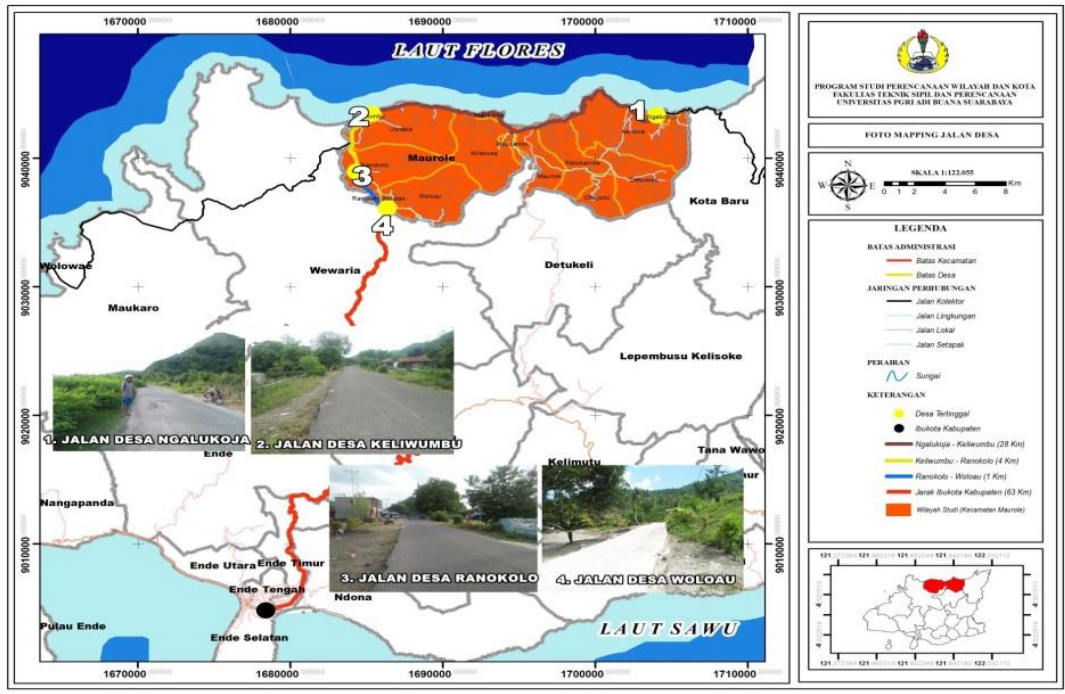

Gambar 8. Peta Mapping Jalan Desa Tertinggal 

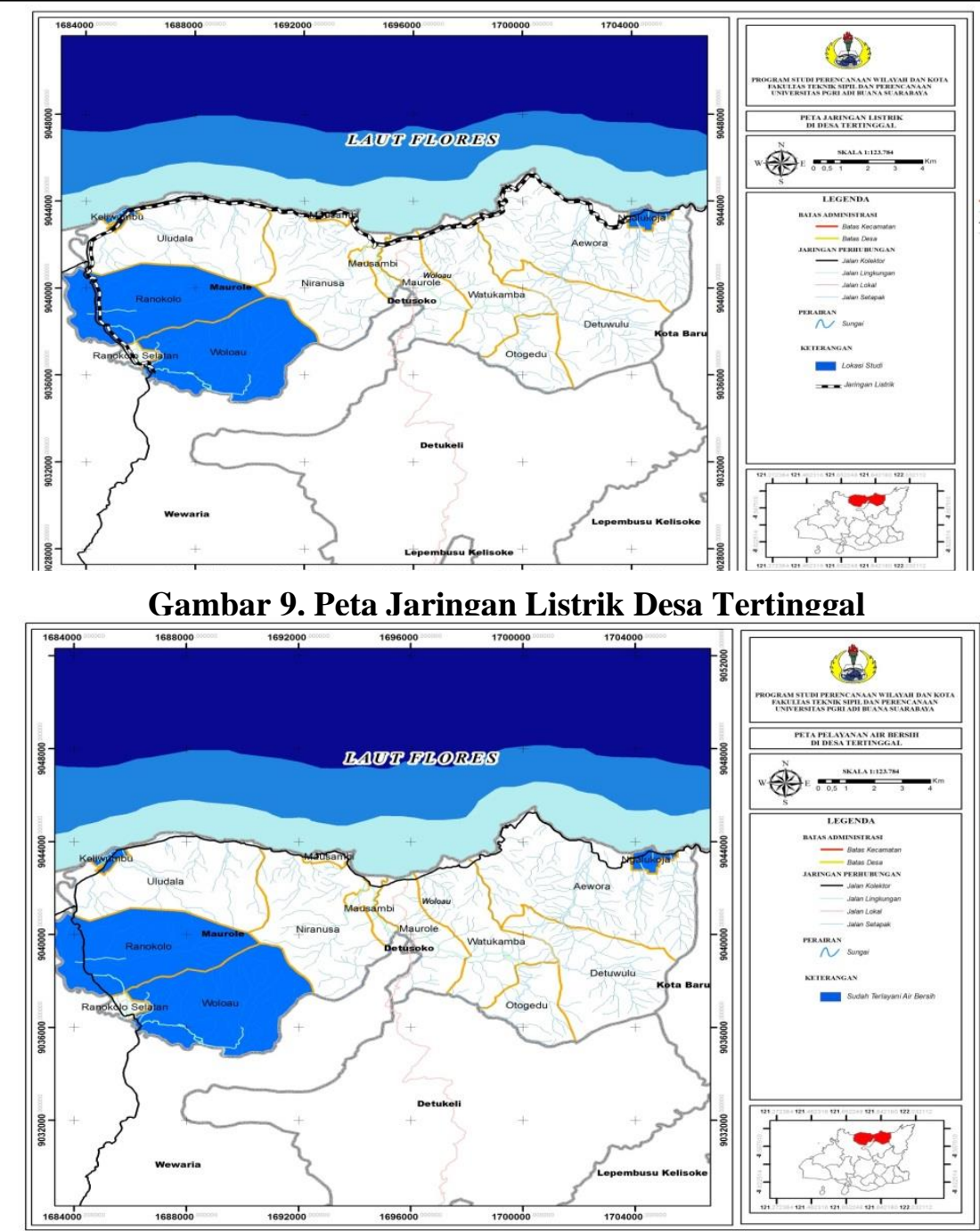

\section{Gambar 10. Peta Pelayanan Air Bersih Desa Tertinggal}

\section{3) Perentase penduduk miskin}

Penduduk miskin desa tertinggal di Kecamatan Maurole, Desa Ranokolo 36\%, Desa Keliwumbu 45\%, Desa Woloau 44\% dan Desa Ngalukoja 39\%. Perbedaan persentasi penduduk miskin masing masing desa memiliki perbedaan beberapa angka saja.

\section{4) Pengeluaran konsumsi perkapita}

Berdasarkan data 2018 diatas pengeluaran konsumsi perkapita desa tertinggal dihitung berdasarkan rata-rata pengeluaran per KK perbulan. Desa yang paling besar ada pada Desa Keliwumbu yaitu Rp 600.000 perbulan. Berdasarkan kondisi pengeluaran konsumsi perkapita desa tertinggal (per KK) di Kecamatan Maurole sudah bisa membiayai hidup anggota keluarganya masing-masing.

15) Angka harapan hidup
Berdasarkan angka harapan hidup desa tertinggal pada tahun 2018 Desa Ranokolo 57,1 dan Desa Keliwumbu 56,9 lebih diatas karena memilki pusat pelayanan terdekat seperti Pustu dan Posyandu, sedangkan Desa Woloau 55,7 dan Desa Ngalukoja 55,6 dengan factor tidak memiliki sama sekali Pusat pelayanan kesehatan terdekat dan hanya terpaut pada pusat pelayanan kesehatan desa tetangga atau puskesmas kecamatan. Jarak tempuh dari desa Woloau menuju Puskesmas $23 \mathrm{Km}$ dan Desa Ngalukoja $16 \mathrm{Km}$.

\section{6) Rata- rata lama sekolah}

Berdasarkan hasil analisis persentase ratarata lama sekolah desa tertinggal merupakan tamatan SD dan SMP. Desa Ranokolo tamatan SD 26\%, Desa Keliwumbu SD 28\% SMP $30 \%$, Desa Woloau SD 31\%, dan Desa Ngalukoja $43 \%$. 


\section{7) Angka melek huruf}

Berdasarkan analisis persentase desa tertinggal masih memiliki angka buta huruf yakni Desa Ranokolo 1,6\%, Desa Keliwumbu 4,3\%, Desa Woloau 7\%, dan Desa Ngalukoja $7,9 \%$.

\section{8) PDRB}

Keuangan desa tertinggal rata- rata telah terlayani oleh pemerintah berupa Dana Desa (DD) dan dan Alokasi Dana Desa (ADD)
Berdasarkan hasil analisis deskriptif kualitatif dan analisis persentase, melihat perkembangan desa tertinggal pada tahun 2018 ini, masih di temukan permasalahanpermasalahan ketertinggalan berdasarkan kondisi fisik dan sosial ekonomi.

\section{Kondisi fisik.}

Permasalahan kondisi fisik desa tertinggal di Kecamatan Maurole dapat dilihat pada Tabel 2.

Tabel 2. Kompilasi Permasalahan Kondisi Fisik Desa Tertinggal Tahun 2018

Kondisi Fisik Ranokolo Keliwumbu Woloau Ngalukoja

Rata-rata jarak dari kantor desa ke

$64 \mathrm{Km}$

$68 \mathrm{Km}$

$63 \mathrm{Km}$

$96 \mathrm{Km}$ kantor kabupaten.

Persentase desa dengan jarak pelayanan kesehatan

Rata-rata jarak dari desa ke pusat pelayanan pendidikan dasar.

Jalan utama desa

Rumah tangga pengguna telepon.

Rumah tangga pengguna listrik.

Rumah tangga pengguna air bersih.

Pasar tanpa bangunan permanen/semi permanen.

Sarana dan prasarana kesehatan per 1000 penduduk.

Jumlah dokter per 1000 penduduk.
200 Meter ke

Polindes

100 Meter

ke Pustu

800 Meter

50 Meter

100 Meter

300 Meter

\section{Aspal 3}

Meter

\section{Aspal 3}

Meter

Semen Beton

2,5 Meter

Aspal 3 Meter

Dijangkau oleh sinyal

$80 \%$

$100 \%$

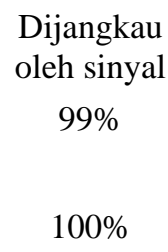

Dijangkau oleh sinyal

$100 \%$

$100 \%$
$100 \%$

Tidak di

jangkau

sinyal

$100 \%$
Tidak Ada

Tidak Ada

Tidak Ada

Tidak Ada 


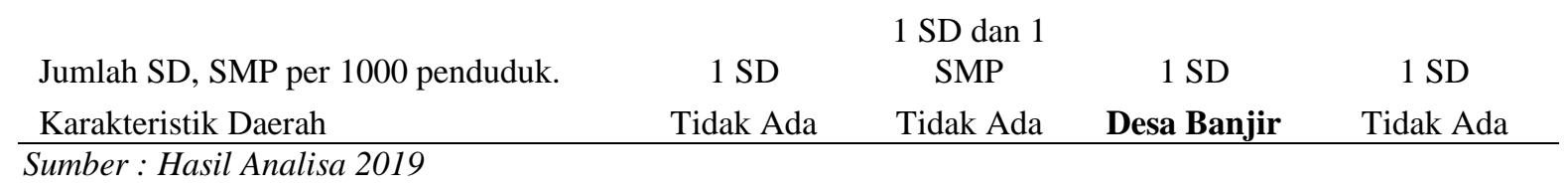

Berdasarkan hasil analisis kondisi fisik pada Tabel 2, 4 desa tertinggal di Kecamatan Maurole yakni Desa Ranokolo, Desa Keliwumbu, Desa Woloau, dan Desa Ngalukoja dalam melihat tingkat perkembangan, ditemukan permasalahan ipada tahun 2018 berdasarkan 12 kriteria antara lain :

a) Desa Ranokolo tidak tersedianya pasar dan jumlah dokter. Jumlah permasalahan berdasarkan 12 kriteria kondisi fisik yaitu $17 \%$ dan yang tidak memiliki permasalahan $83 \%$.

b) Desa Keliwumbu tidak tersedianya pasar dan jumlah dokter. Jumlah permasalahan berdasarkan 12 kriteria kondisi fisik desa tertinggal yaitu $17 \%$ dan yang tidak memiliki permasalahan $83 \%$.

c) Desa Woloau tidak tersedianya sarana kesehatan sehingga masyarakat desa berkonsultasi dan berobat pada sarana kesehatan desa tetangga atau
Puskesmas Kecamatan Maurole. Tidak tersedianya pasar, tidak tersedianya dokter dan Desa woloau juga merupakan desa yang sering mengalami bencana banjir. Jumlah permasalahan berdasarkan 12 kriteria konisi fisik desa tertinggal yaitu sebesar $42 \%$ dan yang tidak memiliki permasalahan $58 \%$.

d) Desa Ngalukoja tidak tersedianya sarana kesehatan sehingga masyarakat desa berkonsultasi dan berobat pada sarana kesehatan desa tetangga dan Puskesmas Kecamatan Maurole. Tidak tersedianya pasar, tidak tersedianya dokter dan tidak memiliki akses informasi yang baik, di karenakan tidak dijangkau oleh jaringan telekomunikasi. Jumlah permasalahan berdasarkan 12 kriteria kondisi fisik desa tertinggal yaitu $42 \%$ dan yang tidak memiliki permasalahan $58 \%$

2. Kondisi Sosial dan Ekonomi.

Permasalahan kondisi sosial dan ekonomi desa tertinggal di Kecamatan Maurole dapat dilihat pada Tabel 3.

Tabel 3 Kompilasi Permasalahan Kondisi Sosial dan Ekonomi Desa Tertinggal Tahun 2018

Kondisi Sosial dan Ekonomi

\section{Ranokolo}

Keliwumbu

Woloau

Ngalukoja

Persentase Penduduk

$36 \%$

$46 \%$

$44 \%$

$39 \%$

miskin

Pengeluaran konsumsi

$\pm 600.000$

$\pm 500.000$

$\pm 400.000$

$\pm 400.000$

perkapita

Angka harapan hidup

57,1

56,9

55,7

55,6 
Rata-rata lama sekolah

Angka melek huruf
SD $26 \%$

$1,6 \%$

Dana Desa dan Alokasi Dana
SD $28 \%$ dan
SMP $30 \%$

$4,3 \%$

Dana Desa dan Alokasi Dana
SD $31 \%$

$7 \%$

Dana Desa dan Alokasi Dana
SD $43 \%$

7,9\%

PDRB. Desa Desa Desa

Dana Desa dan

Alokasi Dana Desa

Sumber : Hasil Analisa 2019

Berdasarkan hasil analisis kondisi sosial dan ekonomi desa tertinggal di Kecamatan Maurole pada Tabel 3, di temukan permasalahan antara lain :

a) Desa Ranokolo memiliki angka harapan hidup 5,71 tahun, rata -rata lama sekolah SD $26 \%$ dan angka melek huruf $1,6 \%$. Jumlah permasalahan berdasarkan 6 kriteria kondisi sosial dan ekonomi desa tertinggal, yaitu $50 \%$.

b) Desa Keliwumbu memiliki 56,9 tahun, rata- rata lama sekolah SD 28\%, SMP $30 \%$ dan angka melek huruf 4,3\%. Jumlah permasalahan berdasarkan 6 kriteria kondisi sosial dan ekonomi desa tertinggal yaitu sebesar $50 \%$.

c) Desa Woloau memiliki angka harapan hidup 55,7 tahun, rata-rata lama sekolah SD 31\% dan angka melek huruf $7 \%$. Jumlah permasalahan berdasarkan 6 kriteria kondisi sosial dan ekonomi desa tertinggal yaitu sebesar $50 \%$.

d) Desa Ngalukoja memiliki angka harapan hidup 55,6 tahun, rata-rata lama sekolah SD $43 \%$ dan angka melek huruf $7,9 \%$. Jumlah permasalahan berdasarkan 6 kriteria kondisi sosial dan ekonomi desa tertinggal yaitu sebesar $50 \%$.

\section{KESIMPULAN}

Berdasarkan tingkat perkembangan 4 desa tertinggal dari kondisi fisik dan sosial ekonomi desa tertinggal di Kecamatan Maurole pada tahun 2018 yakni, Desa Ranokolo, Desa Keliwumbu, Desa Woloau, dan Desa Ngalukoja disimpulkan :

1. Permasalahan 4 desa tertinggal di Kecamatan Maurole berdasarkan 12 kriteria kondisi fisik, rata-rata dibawah $50 \%$. Permasalahan tersebut antara lain : Desa Ranokolo 17\% (tidak tersedianya pasar dan dokter), Desa Keliwumbu17\% (tidak tersedianya pasar dan dokter), Desa Woloau 42\% (tidak tersedianya pasar, dokter, sarana kesehatan, dan desa rawan bencana), Desa Ngalukoja 42\% (tidak tersedianya pasar, dokter, sarana kesehatan, dan tidak jangkau oleh sinyal). Berdasarkan permasalahan diatas, pada tahun 2018, Desa Ranokolo, Desa Keliwumbu, Desa Woloau dan Desa Ngalukoja mengalami perkembangan dari 12 kriteria kondisi fisik Desa Ranokolo dan Desa Keliwumbu 83\%, sedangkan Desa Woloau dan Desa Ngalukoja 58\%.

2. Permasalahan yang dihadapai oleh 4 desa tertinggal di Kecamatan Maurole berdasarkan 6 kriteria kondisi sosial dan ekonomi rata- rata masih 50\%. Berdasarkan hasil pembahasan, 4 desa tertinggal memiliki permasalahan yang sama yakni, angka harapan hidup 50\%, rata-rata lama sekolah $50 \%$ dan angka melek huruf $50 \%$. Berdasarkan permasalahan diatas, tingkat perkembangan 4 desa tertinggal di Kecamatan Maurole dalam hal kondisi sosial dan ekonomi pada tahun 2018 masih belum ada perkembangan yang signifikan. 


\section{UCAPAN TERIMAKASIH}

Ucapan terima kasih dan penghargaan perlu penulis sampaikan kepada Tuhan Yang Maha Esa serta berbagai pihak yang telah memberikan bantuan berupa bimbingan, arahan, saran, dukungan. Tidak lupa ucapan terima kasih kami sampaikan kepada; Kedua Orang Tua, Kantor Camat Maurole, Kantor Desa Ranokolo, Keliwumbu, Woloau dan Ngalukoja yang telah membantu dalam memperoleh data.

\section{DAFTAR PUSTAKA}

Anonim. (2016). Keputusan Menteri Desa, Pembangunan Daerah Tertinggal dan Transmigrasi No. 3 Tahun 2016, tentang Petuntuk Teknis Penentuan Indikator Dalam Penetapan daerah Tertinggal Secara Nasional. Jakarta: Kementerian Desa, Pembangunan Daerah Tertinggal dan Transmigrasi.

Anonim. (2017). Keputusan Menteri Desa, Pembangunan Daerah Tertinggal dan Transmigrasi Nomor 126 Tahun 2017, tentang Penetapan Desa Prioritas Sasaran Pembangunan Desa, Pembangunan Daerah Tertinggal Dan Transmigrasi. Jakarta: Kementerian Desa, Pembangunan Daerah Tertinggal dan Transmigrasi.

Anonim. (2015). Peraturan Presiden Republik Indonesia Nomor 131 tahun 2015, tentang Penetapan Daerah Tertinggal Tahun 2015-2019. Jakarta: Presiden Republik Indonesia.

Anonim. (2018). Peraturan Menteri Desa, Pembangunan Daerah Tertinggal dan Transmigrasi Nomor 19 Tahun 2017, tentang Penetapan Prioritas Penggunaan Dana Desa 2018. Jakarta: Kementerian Desa, Pembangunan Daerah Tertinggal dan Transmigrasi.

Anonim. (2018). Kecamatan Maurole dalam Angka 2018.

Anonim (2018). Kantor Camat Maurole ( Pendataan Podes BPS)2018.

Anonim (2018). Kantor Desa Ranokolo ( Pendataan Podes BPS)2018.

Anonim (2018). Kantor Desa Keliwumbu ( Pendataan Podes BPS)2018.

Anonim (2018). Kantor Desa Woloau ( Pendataan Podes BPS)2018.

Anonim (2018). Kantor Desa Ngalukoja ( Pendataan Podes BPS)2018.

Gae, Kristianus Resi. (2018). Analisis Linkage system Pariwisata di Kabupaten Ngada. Skripsi Jurusan Perencanaan Wilayah dan Kota Universitas Adibuana Surabaya.

Muhtar dkk. (2011). Masyarakat Desa Tertinggal Jurnal Penelitian dan Pengembangan Kesejahteraan Sosial. Volume 16. No 1. 